\title{
Expression of Functional Tyrosine Kinase B Receptors by Rhythmically Active Respiratory Neurons in the Pre- Bötzinger Complex of Neonatal Mice
}

\author{
Muriel Thoby-Brisson, ${ }^{1}$ Bruno Cauli, ${ }^{3}$ Jean Champagnat, ${ }^{1}$ Gilles Fortin, ${ }^{1}$ and David M. Katz ${ }^{2}$ \\ ${ }^{1}$ Laboratoire de Neurobiologie Génétique et Intégrative, Institut Alfred Fessard, Centre National de la Recherche Scientifique, 91198 Gif sur Yvette, France, \\ 2Department of Neurosciences, Case Western Reserve University School of Medicine, Cleveland, Ohio 44106, and ${ }^{3}$ Neurobiologie et Diversité Cellulaire, \\ Centre National de la Recherche Scientifique and Ecole Supérieure de Physique et Chimie Industrielles, 75231 Paris, France
}

\begin{abstract}
Genetic loss of brain-derived neurotrophic factor (BDNF) severely disrupts brainstem control of respiratory rhythmogenesis in newborn mice; however, the sites at which BDNF acts to regulate respiratory rhythmogenesis are unknown. Using immunochemical and multiplex RT-PCR analysis in mouse brainstem slices, we report that the BDNF receptor, Tyrosine kinase B (TrkB), is strongly expressed in the pre-Bötzinger complex (PBC), the presumed site for rhythm generation, and colocalizes with neurokinin 1 (NK1), a marker of neurons critical for breathing. The period of the respiratory rhythm generated by $\mathrm{PBC}$ neurons in vitro was increased by $30 \%$ after BDNF treatment $(100 \mathrm{ng} / \mathrm{ml})$ and not by nerve growth factor $(100 \mathrm{ng} / \mathrm{ml})$ or BDNF $(100 \mathrm{ng} / \mathrm{ml})$ in the presence of the tyrosine kinase inhibitor K252a $(200$ $\mathrm{nM})$. Both synaptic and voltage-dependent properties of $\mathrm{PBC}$ neurons were modified by BDNF. Synaptic currents underlying spontaneous rhythmic bursts and glutamate-evoked currents were enhanced by 66 and 33\%, respectively. BDNF reduced the $I_{\mathrm{h}}$ current amplitude in rhythmic neurons by $46 \%$ and shifted its activation curve by $-17 \mathrm{mV}$. All neurons expressing $\operatorname{TrkB} \mathrm{mRNA}(n=8)$ also expressed mRNAs for the $I_{\mathrm{h}}$ current [hyperpolarization-activated cyclic nucleotide-sensitive cation nonselective channel (HCN1)], and three of four NK1positive neurons coexpressed TrkB and HCN mRNA. Six of 16 PBC neurons expressed BDNF mRNA, supporting the possibility of autocrine and paracrine actions of BDNF within the respiratory pattern generator. Our data demonstrate that BDNF can modulate respiratory network activity through TrkB signaling in rhythmic $\mathrm{PBC}$ neurons.
\end{abstract}

Key words: respiration; rhythmic neurons; BDNF; TrkB; pre-Bötzinger complex; RT-PCR

\section{Introduction}

The respiratory rhythm is generated by a neural network located within the caudal ventrolateral medulla in the pre-Bötzinger complex (PBC) (Smith et al., 1991; Rekling and Feldman, 1998). The PBC contains all elements sufficient for generation of the respiratory rhythm in slice preparations (Smith et al., 1991), and lesioning of the $\mathrm{PBC}$ in vivo abolishes breathing (Koshiya and Guyenet, 1998; Ramirez et al., 1998). The PBC includes a glutamatergic network of rhythmic neurons (Bianchi et al., 1995; Ramirez et al., 1997) that express the hyperpolarization-activated cationic current $I_{\mathrm{h}}$ (Rekling et al., 1996; Thoby-Brisson et al., 2000) and the substance P receptor neurokinin 1 (NK1) (Gray et al., 1999; Wang et al., 2001).

Development of the respiratory rhythm is severely disrupted

Received March 25, 2003; revised June 30, 2003; accepted June 30, 2003.

This work was supported by the Fondation pour la Recherche Médicale to M.T.B., by a European grant (QLG2/CT/ 2001-01467) and Action Concerteé Incitative Biologie du Dèveloppement et Physiologie Integrative Direction Générale des Armées to the Laboratoire de Neurobiologie Génétique et Intégrative, and by the National Institutes of Health (NHLBI) to D.M.K. We thank Sandra Autran for helpful technical assistance in immunostaining and PCR experiments.

Correspondence should be addressed to Dr. Muriel Thoby-Brisson, Laboratoire de Neurobiologie Génétique et Intégrative, Institut Alfred Fessard, Centre National de la Recherche Scientifique, 1 Avenue de la Terrasse, 91198 Gif sur Yvette, France. E-mail: muriel.thoby-brisson@iaf.cnrs-gifffr.

Copyright $\odot 2003$ Society for Neuroscience $\quad$ 0270-6474/03/237685-05\$15.00/0 in newborn mice carrying a targeted deletion in the gene encoding brain-derived neurotrophic factor (BDNF) (Erickson et al., 1996; Balkowiec and Katz, 1998), a member of the neurotrophin family of growth factors. In particular, central respiratory output and ventilation are depressed and irregular in BDNF null mutants, and the animals die shortly after birth. Whether these deficits reflect developmental or acute roles, or both, for BDNF in respiratory rhythmogenesis has not been defined. In addition to its importance as a neuronal survival factor, BDNF also regulates synaptic plasticity (Lu, 2003) and neuronal membrane conductances (Blum et al., 2002). Therefore, to address the possibility that BDNF plays an acute role in the modulation of respiratory rhythmogenesis, the present study examined expression of the BDNF receptor, Tyrosine kinase B (TrkB), as well as the effects of BDNF application, in rhythmic PBC neurons in neonatal mice.

\section{Materials and Methods}

Slice preparation. Experiments were performed in transverse brainstem slices obtained from 1- to 4-d-old OF1 mice. Animals were deeply anesthetized by hypothermia and then decapitated at the C3-C4 level. The brainstem was trimmed by serially sectioning in the transverse plane from rostral to caudal until the PBC was reached (Ramirez et al., 1996). A $400-\mu \mathrm{M}$-thick slice, containing the $\mathrm{PBC}$ at its rostral surface, was then removed, placed in a recording chamber maintained at $30^{\circ} \mathrm{C}$, and perfused continuously with oxygenated artificial CSF (ACSF). ACSF com- 
position was (in mM): $128 \mathrm{NaCl}, 8 \mathrm{KCl}, 1.5 \mathrm{CaCl}_{2}, 1 \mathrm{MgSO}_{4}, 24 \mathrm{NaHCO}$, $0.5 \mathrm{Na}_{2} \mathrm{HPO}_{4}, 30$ glucose, $\mathrm{pH}$ 7.4. All experiments were performed in accordance with ethical guidelines defined by the French Agricultural Ministry and the European Union Council Directive for the Care and Use of Laboratory Animals (no. 2889).

Recordings. Extracellular population activity was recorded with an electrode positioned on the PBC at the surface of the slice. The signal was amplified using a high-gain AC amplifier (Grass, 7P511), filtered (lowpass $3 \mathrm{kHz}$, high-pass $3 \mathrm{~Hz}$ ), and integrated using an electronic filter (Neurolog System; time constant $100 \mathrm{msec}$ ). Whole-cell patch-clamp recordings ( $n=37$ ) were performed under visual control using differential interference contrast and infrared video microscopy, an Axoclamp2A amplifier (Axon Instruments, Foster city, CA), a digitizing interface (Digidata 1322A, Axon Instruments), and the software program pClamp8 (Axon Instruments). Neurons examined were type 2 nonpacemaker inspiratory neurons (Rekling et al., 1996; Thoby-Brisson et al., 2000) located ventral to the nucleus ambiguus and within $80-100 \mu \mathrm{m}$ of the extracellular electrode. Patch electrodes were manufactured from borosilicate glass tubes containing a filament (Clark GC 150TF, Pangbourn, UK) and filled with a solution containing (in $\mathrm{mM}$ ): 140 K-gluconic acid, $1 \mathrm{CaCl}_{2}, 10$ EGTA, $2 \mathrm{MgCl}_{2}, 4 \mathrm{Na}_{2}$-ATP, 10 HEPES, pH 7.2, and $0.05 \mathrm{mg} / \mathrm{l}$ Alexa Fluor 594 (Molecular Probes, Eugene, OR). The pipette resistance was 4-6 M $\Omega$ when the electrodes were filled with solution. Membrane potentials were corrected for liquid junction potentials.

The $I_{\mathrm{h}}$ current was evoked by a series of $2 \mathrm{sec}$ hyperpolarizing voltage pulses incrementing in $10 \mathrm{mV}$ steps from a holding potential of $-50 \mathrm{mV}$, applied between inspiratory bursts (see Fig. 3C1). The difference between current amplitudes measured at the beginning and the end of each voltage step gave the net $I_{\mathrm{h}}$ current amplitude. No leak subtraction was performed. Activation curves were obtained by converting peak current to peak conductance, assuming a reversal potential of $-28 \mathrm{mV}$ [assessed by the extrapolation method of Mironov et al. (2000)]. These values were then normalized to the calculated $g_{\max }$, and the resulting conductancevoltage curves were fitted to a first order Boltzmann equation $\left(\mathrm{g} / \mathrm{g}_{\max }=\right.$ $1 /\left(1+\exp ^{\left(\mathrm{V}_{1 / 2}-\mathrm{V}\right) / \mathrm{s}}\right)$ in which $V_{1 / 2}$ is the mean voltage for half-maximal activation and $s$ the slope. Long-term recordings without any pharmacological treatment showed no $I_{\mathrm{h}}$ run down (data not shown).

Additional reagents included BDNF (Promega, Madison, WI), 100 ng/ml; NGF (Promega), 100 ng/ml; K252a (Calbiochem, La Jolla, CA), 200 nM; glutamate (Sigma, St. Louis, MO), 1 mm. Because BDNF effects were only partially reversible, each brainstem slice was exposed to BDNF only once.

Data were analyzed off-line using Clampfit software (Axon Instruments). Statistical values are given as mean \pm SEM. Significance $(p<$ 0.05 ) was determined by Student's $t$ test or one-way ANOVA.

Single-cell multiplex RT-PCR. RT-PCR was performed on PBC neurons that had been characterized with respect to electrophysiological phenotype and $I_{\mathrm{h}}$ currents within the first $10 \mathrm{~min}$ after establishment of the whole-cell patch. The cytoplasm was then harvested for RT-PCR to minimize any potential mRNA degradation that could occur with longer recording times (Lambolez et al., 1992). This requirement to harvest quickly after patching precluded analysis of BDNF responsiveness in cells selected for RT-PCR, because at least 15 min were required to observe significant responses to BDNF. The cytoplasm was aspirated into the recording pipette under visual and electrophysiological control by application of a gentle negative pressure. The contents of the pipette were then expelled into a microcentrifuge tube and reverse transcription was performed in a final volume of $10 \mu \mathrm{l}$. Control experiments performed in cell-attached configuration showed no mRNA contamination.

Multiplex PCR was performed essentially as described previously (Cauli et al., 1997). The protocol was designed to simultaneously detect expression of BDNF, TrkB, NK1, and the hyperpolarization-activated cyclic nucleotide-sensitive cation nonselective channel HCN1 (Santoro et al., 2000) mRNAs. Genomic DNA amplification, which could occur if the nucleus was harvested, was systematically assessed using a somatostatin gene intron as a genomic control. The cDNAs contained in the $10 \mu \mathrm{l}$ reverse transcription reaction were first amplified by 20 PCR cycles $\left(94^{\circ} \mathrm{C}, 30 \mathrm{sec} ; 60^{\circ} \mathrm{C}, 30 \mathrm{sec} ; 72^{\circ} \mathrm{C}, 35 \mathrm{sec}\right)$ using $2.5 \mathrm{U}$ of $\mathrm{Taq}$ polymerase
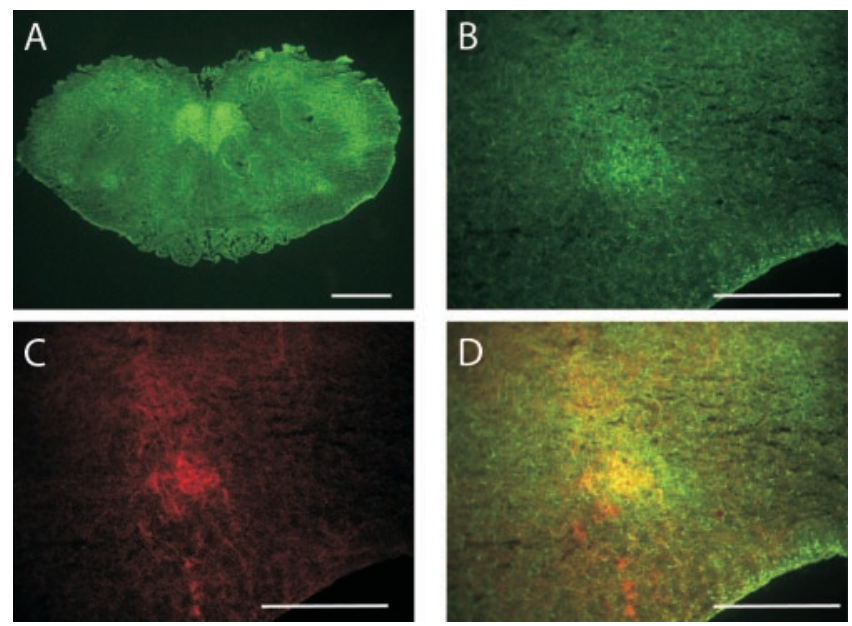

Figure 1. NK1 and TrkB immunoreactivity in the newborn mouse caudal medulla. $A$, TrkB is prominent in the $P B C$ region (shown at higher magnification in $B$ ) and hypoglossal nucleus (XII). $C$, NK1 in the PBC. D, Merged image of $B$ and $C$; yellow indicates colocalization of NK1 and TrkB. Scale bars: $A, 1 \mathrm{~mm} ; B-D, 50 \mu \mathrm{m}$.

(Qiagen) and 10 pmol of each of the following sets of primers (from $5^{\prime}$ to $3^{\prime}$, position 1 being the first base of the initiation codon except for somatostatin intron) were added in the buffer supplied by the manufacturer (final volume, $100 \mu \mathrm{l}$ ): ATGTCTATGAGGGTTCGGCG (BDNF sense, position 370), GCGAGTTCCAGTGCCTTTTG (BDNF antisense, 606), ACTGTGAGAGGCAACCCCAA (TrkB sense, 916), ATCACCAGCAGGCAGAATCC (TrkB antisense, 1327), CATCTTCAACCACCACCCCA (HCN1 sense, position 1916), GACGCAGTGGGAGAGGCATA (HCN1 antisense, position 2122), TTCCCCAACACCTCCACCAA (NK1 sense, position 34), AGCCAGGACCCAGATGACAA (NK1 antisense, position 455), CTGTCCCCCTTACGAATCCC (somatostatin intron sense, 8), CCAGCACCAGGGATAGAGCC (somatostatin intron antisense, 228). Thirty-five cycles of PCR were then performed using $2 \mu$ lof the first PCR product as template and using the same primers generating PCR fragments of 256, 431, 226, 441, and 208 bp for BDNF, TrkB, HCN1, NK1, and somatostatin intron, respectively. Ten microliters of each individual second-step PCR reaction were then run on a $1.5 \%$ agarose gel using Фx174 cut by HaeIII as molecular weight markers (with bands of 1353 , $1078,872,603,310,281,271,234,194,118$, and $72 \mathrm{bp}$ ) and stained with ethidium bromide. All cells positive for somatostatin intron were discarded from the analysis $(n=5)$. The specificity of the RT-multiplex PCR (mPCR) procedure was tested on $50 \mathrm{ng}$ of total RNAs extracted from brainstem slices (data not shown).

Immunostaining. Brainstem slices were fixed overnight in $4 \%$ paraformaldehyde and then cryoprotected in 30\% sucrose-PBS. Slices were resectioned at $20-30 \mu \mathrm{m}$ in a cryostat and mounted onto glass slides. For TrkB and NK1 double immunostaining, sections were incubated for 30 min in $1 \%$ BSA and $0.5 \%$ Triton X-100, followed by affinity-purified chicken anti-TrkB (1:100, Promega) and rabbit anti-NK1 (1:5000, Sigma) overnight at room temperature. After rinsing in PBS, sections were incubated sequentially in biotin-conjugated goat anti-chicken IgG $(1: 1000,3 \mathrm{hr}$; Rockland) and Alexa Fluor 594-conjugated goat antirabbit IgG (1:400; Molecular Probes), streptavidin-HRP (1:100, 30 min; Molecular Probes), and Alexa Fluor 488-Tyramide (1:100, Molecular Probes). Sections were coverslipped and mounted in PBS-glycerol. Control experiments in which the primary antibodies were replaced by normal serum exhibited no labeling.

\section{Results}

\section{The PBC exhibits TrkB immunostaining}

To examine whether BDNF could act at the level of the PBC to influence respiratory rhythmogenesis, initial studies sought to define the distribution of TrkB immunoreactivity in relation to the substance P receptor, NK1, which is highly expressed by neu- 

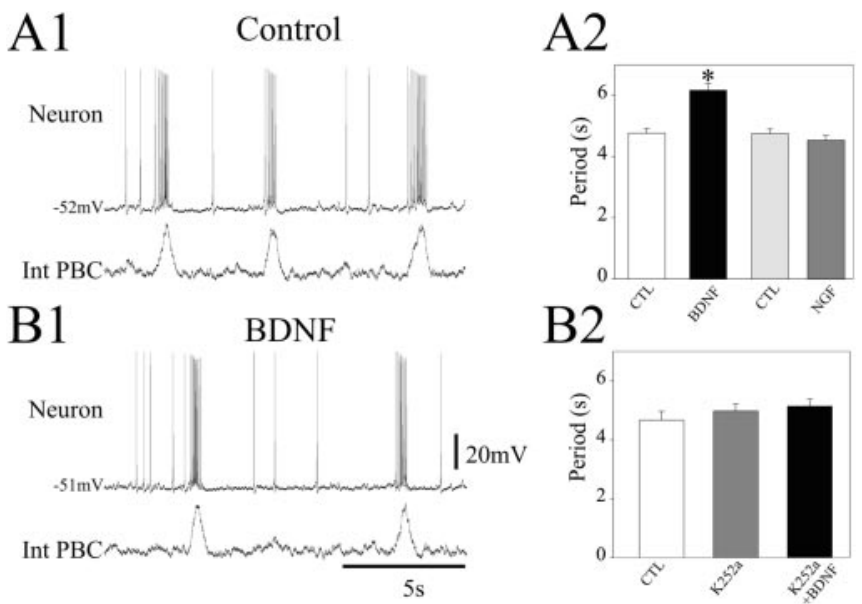

Figure 2. BDNF decreases respiratory frequency in vitro. $A$, Intracellular recordings from a $\mathrm{PBC}$ neuron (top traces) recorded simultaneously with integrated population activity (bottom traces) in control ( $A 1$ ) and in the presence of $100 \mathrm{ng} / \mathrm{ml}$ BDNF (B1). A2, Bar histograms showing the mean period of rhythmic activity in the presence of either BDNF or NGF and their respective control (CTL) (BDNF control, white bar; $n=12$ ), $100 \mathrm{ng} / \mathrm{ml} \mathrm{BDNF}$ (black bar; $n=12$ ), NGF control (light gray bar; $n=6$ ), and $100 \mathrm{ng} / \mathrm{ml} \mathrm{NGF}$ (dark gray bar, $n=6$ ). B2, Bar histograms depicting the mean period of rhythmic activity $(n=6)$ in control conditions (white bar), $200 \mathrm{~nm}$ K252a (gray bar), and $200 \mathrm{~nm} \mathrm{K252a} \mathrm{plus} 100 \mathrm{ng} / \mathrm{ml}$ BDNF (black bar). BDNF effects are abolished in the presence of $\mathrm{K} 252 \mathrm{a}$. ${ }^{*} p<0.05$.

rons of the ventral respiratory group (Gray et al., 1999; Wang et al., 2001). We observed prominent TrkB immunoreactivity in several regions of the newborn mouse brainstem (Fig. 1A), including ventromedial to the nucleus ambiguus (Fig. $1 B$ ) in an area corresponding to the PBC. This region also exhibited NK1 immunoreactivity (Fig. 1C), and TrkB and NK1 appeared to mark partially overlapping populations of neurons within the PBC (Fig. 1D).

\section{BDNF modulates rhythmic output from the PBC}

In all slices examined $(n=12)$, bath application of BDNF (100 $\mathrm{ng} / \mathrm{ml}, 30 \mathrm{~min}$ ) induced a $30.5 \%$ increase in the mean period of population bursts recorded extracellularly from the PBC ( $4.74 \pm$ $0.15 \mathrm{sec}$ under control conditions vs $6.19 \pm 0.22 \mathrm{sec}$ in treated slices; $p<0.05$ ) (Fig. $2 A 1, A 2, B 1$ ) without any change in resting membrane potential $(-51.6 \pm 3.8 \mathrm{mV}$ under control conditions vs $-50.9 \pm 5.0 \mathrm{mV}$ in the presence of BDNF) (Fig. $2 A 1, B 1$ ). This response began $15 \mathrm{~min}$ after BDNF application. No effect was observed after treatment with NGF (100 ng/ml; $n=6)$, another member of the neurotrophin family that shares a high degree of sequence homology with BDNF yet acts through a different receptor tyrosine kinase, TrkA (Fig. 2A2). To determine whether BDNF modulation of the $\mathrm{PBC}$ rhythm requires activation of the TrkB receptor, an additional six brainstem slices were exposed to the tyrosine receptor kinase inhibitor K252a (200 nM) for $1 \mathrm{hr}$. As shown in Figure 2B2, the respiratory period was comparable in control conditions, in the presence of K252a alone, and in the presence of K252a plus BDNF (control, $4.60 \pm 0.24 \mathrm{sec}$; K252a, $4.97 \pm 0.23 \mathrm{sec} ; \mathrm{BDNF}+\mathrm{K} 252 \mathrm{a}, 5.13 \pm 0.22 \mathrm{sec} ; p>0.05$; one-way ANOVA), consistent with a role for TrkB in mediating BDNF modulation of population activity in the PBC.

BDNF enhances excitatory synaptic currents in PBC neurons To test the possibility that BDNF targets excitatory processing in the respiratory network, we examined the effect of BDNF on the glutamatergic excitatory synaptic drive underlying rhythmic
A1

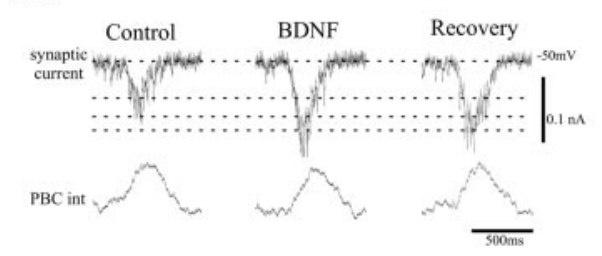

A2

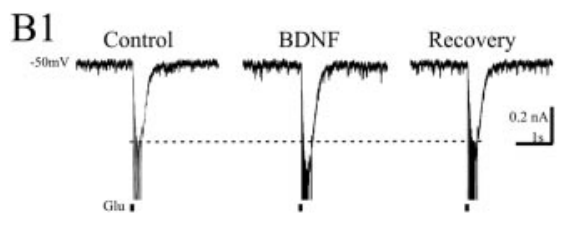

B2

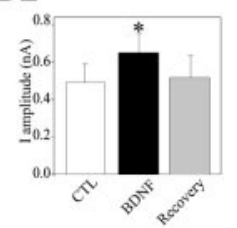

$\mathrm{C} 1$

$\mathrm{C} 2$
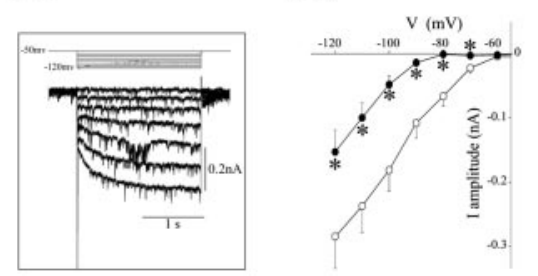

C3

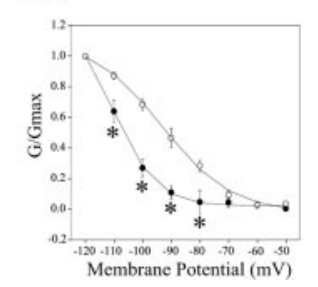

Figure 3. BDNF affects excitatory processes in $P B C$ neurons. $A 1$, Synaptic currents (top traces) recorded from a $\mathrm{PBC}$ neuron during a burst of $\mathrm{PBC}$ population activity (bottom traces; integrated signal) were recorded in control conditions (left), in $100 \mathrm{ng} / \mathrm{ml}$ BDNF (middle), and after 30 min washout (right). Dashed lines indicate the different amplitudes obtained under each condition. $A 2$, Histogram depicting the mean current amplitude measured in control conditions (CTL; white bar), in the presence of BDNF (black bar), and after 30 min washout (gray bar). $B 1$, Current evoked by pressure application of $1 \mathrm{~mm}$ glutamate (black squares) in control conditions (left), in the presence of $100 \mathrm{ng} / \mathrm{ml} \mathrm{BDNF}$ (middle), and after 30 min washout (right). Unclamped action potentials were truncated. B2, Same as in $A 2$. C1, Stimulation protocol used to evoke the $I_{\mathrm{h}}$ current and $I_{\mathrm{h}}$ raw current traces. $\left(2\right.$, Graph of $I_{\mathrm{h}}$ versus voltage. Evoked currents were measured as described in Materials and Methods in control conditions $(\bigcirc)$ and after 30 min exposure to $100 \mathrm{ng} / \mathrm{ml}$ BDNF $(\bullet)$. C $3, I_{\mathrm{h}}$ current activation curves obtained in control conditions $(\bigcirc)$ and in the presence of $100 \mathrm{ng} / \mathrm{ml} \operatorname{BDNF}(\Theta)$. The data were fitted to a first order Boltzmann relation (lines). ${ }^{*} p<0.05$; one-way ANOVA.

burst discharges and glutamate-evoked synaptic currents in PBC neurons. In the first set of experiments, five neurons from five different slices were held at $-50 \mathrm{mV}$, and the amplitude of spontaneous rhythmic synaptic currents was measured in control conditions, in the presence of $100 \mathrm{ng} / \mathrm{ml} \mathrm{BDNF}$, and after $30 \mathrm{~min}$ washout (Fig. 3A1). The amplitude of spontaneous rhythmic synaptic currents (mean of 10 consecutive rhythmic bursts) increased significantly from $41 \pm 10 \mathrm{pA}$ in control to $68 \pm 14 \mathrm{pA}$ in the presence of BDNF (Fig. 3A2) as did duration ( $0.40 \pm 0.02 \mathrm{sec}$ in controls vs $0.54 \pm 0.03 \mathrm{sec}$ in the presence of BDNF). These effects were only partially reversible after $30 \mathrm{~min}$ recovery, because the mean current amplitude remained elevated at $62 \pm 16$ $\mathrm{pA}$ and the mean duration remained at $0.51 \pm 0.01 \mathrm{sec}$. This may reflect either persistence of BDNF in the tissue or activation of long-term signaling mechanisms downstream of the TrkB receptor (Huang and Reichardt, 2001).

An additional six neurons were exposed to glutamate pulses (1 $\mathrm{mm}$, applied between two inspiratory bursts). This paradigm, which neither triggered population bursts nor modified ongoing rhythmic activity, allowed individual cellular responses to be tested without affecting the entire neural network. The neurons were held at $-50 \mathrm{mV}$, and puffs of glutamate ( $100 \mathrm{msec}, 5 \mathrm{psi}$ ) were delivered by pressure once every minute from a microelectrode positioned $20-40 \mu \mathrm{m}$ from the patch pipette. Glutamateevoked inward current increased in the presence of BDNF (from 

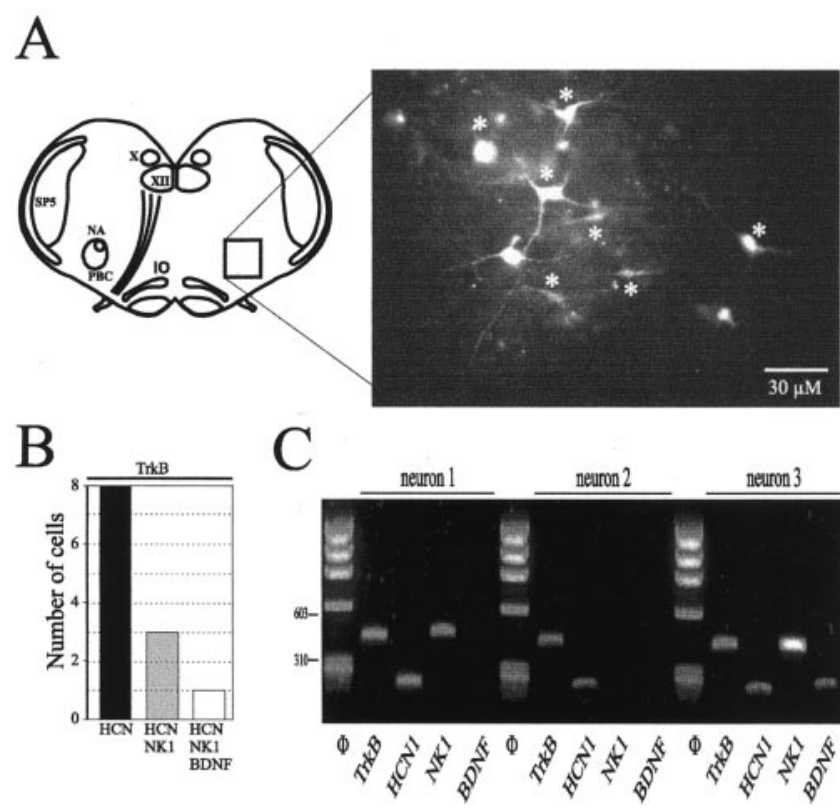

Figure 4. $\quad P B C$ neurons express TrkB, HCN, NK1, and BDNF mRNAs. A, Left, Schematic diagram of a transverse brainstem slice. The rectangle outlines the PBC, illustrated at higher magnification in the right panel. Right, Intracellular labeling with Alexa Fluor 594 of seven rhythmic PBC neurons analyzed by RT-PCR (asterisks). Labeled, unmarked neurons were not rhythmic and therefore not analyzed by RT-PCR. $B$, Graph depicting the numbers of TrkB-positive PBC neurons expressing different combinations of HCN, NK1, and BDNF mRNAs. C, Agarose gel analysis of the multiplex RT-PCR products of three PBC neurons. $\Phi$ indicates molecular weight markers. I0, Inferior olive; NA, nucleus ambiguus; PBC, pre-Bötzinger complex; Sp5, spinal trigeminal nucleus; $X$, dorsal motor nucleus of vagus; XII, hypoglossal nucleus.

$0.49 \pm 0.10 \mathrm{nA}$ in control to $0.65 \pm 0.12 \mathrm{nA}$ in the presence of BDNF; $p<0.05$ ) (Fig. 3B1,B2). This effect was not completely reversible within the time period examined because the amplitude of glutamate-evoked currents remained at $7 \%$ above control values $30 \mathrm{~min}$ after washout (Fig. 3B2). From these experiments we conclude that BDNF can act at postsynaptic sites to enhance the strength of excitatory synaptic coupling among PBC neurons.

\section{BDNF modulates $I_{\mathrm{h}}$ current properties in PBC neurons}

The decrease in respiratory frequency observed after BDNF treatment could also reflect modulation of intrinsic neuronal properties. In 8 of 10 neurons, the $I_{\mathrm{h}}$ current (Fig. $3 C 1$ ) exhibited a significant decrease in amplitude in response to BDNF (Fig. 3C2). Mean current amplitude evoked with a test pulse to $-120 \mathrm{mV}$ decreased from $-0.28 \pm 0.04 \mathrm{nA}$ in control conditions to $-0.15 \pm 0.03 \mathrm{nA}$ after BDNF treatment. In addition, the activation curve for the $I_{\mathrm{h}}$ current shifted toward more hyperpolarized potentials in the presence of BDNF (Fig. 3C3). Boltzmann fits gave a mean voltage for half-maximal activation $V_{1 / 2}=-110.2 \pm$ $0.8 \mathrm{mV}$ and a slope $s=7.5$ in the presence of BDNF, and $V_{1 / 2}=$ $-93.41 \pm 1.2 \mathrm{mV}$ and $s=12$ in control conditions [the values that we obtained for $V_{1 / 2}$ were more hyperpolarized than described for other types of neurons (Magee, 1998; Santoro et al., 2000)]. These experiments demonstrate that BDNF reduces the contribution of the $I_{\mathrm{h}}$ current to voltage-dependent properties of PBC neurons. BDNF induced no modifications in $I-V$ curves, TEA-sensitive outward currents, and leak currents.

\section{Individual $\mathrm{PBC}$ neurons express TrkB or $\mathrm{BDNF}$, or both}

To further define the molecular basis of BDNF responsiveness in the PBC, we examined expression of mRNAs encoding TrkB,
$\mathrm{NK} 1, \mathrm{HCN} 1$, and BDNF in individual PBC neurons $(n=16)$ from six slices using multiplex RT-PCR (Fig. 4A). In keeping with our electrophysiological data indicating a link between TrkB and the $I_{\mathrm{h}}$ current, all TrkB-positive neurons $(n=8)$ expressed HCN1 mRNA (Fig. 4B, C, neurons 1-3). Three neurons coexpressed TrkB and NK1 (Fig. $4 B, C$, neurons 1 and 3 ). We found one neuron positive for all four markers (Fig. $4 B, C$, neuron 3 ). In addition, 6 of 16 PBC neurons, 2 of which expressed TrkB mRNA, expressed BDNF mRNA (Fig. 4B, $C$, neuron 3). Together, these results demonstrate that (1) half of the PBC neurons sampled express TrkB mRNA, consistent with the possibility that BDNF acts directly on PBC neurons to modulate central respiratory activity, and (2) some PBC neurons themselves may be a source of BDNF.

\section{Discussion}

Our results demonstrate that $\mathrm{BDNF}$ can regulate respiratory rhythmogenesis by modulating activity of rhythmically active neurons in the PBC. First, we observed strong expression of the $\mathrm{BDNF}$ receptor, TrkB, in the $\mathrm{PBC}$, as well as colocalization of TrkB and NK1, a marker of a subtype of respiratory neurons in this region (Gray et al., 1999). Second, we found that bath application of BDNF to spontaneously active brainstem slices significantly decreased respiratory frequency generated in the PBC. This effect was associated with an enhancement of excitatory synaptic currents in $\mathrm{PBC}$ neurons and modifications of $I_{\mathrm{h}}$ current properties. Third, single-cell RT-PCR analysis demonstrated that individual $\mathrm{PBC}$ neurons express TrkB, consistent with a direct action of BDNF on these cells. Altogether, our data indicate that a large subset of $\mathrm{PBC}$ neurons, including cells involved in generating or regulating the respiratory rhythm, respond to BDNF. Approximately one of five neurons coexpressed TrkB and NK1 receptor mRNAs, because NK1 neurons are required for normal breathing (Gray et al., 2001); this cell population is a likely target at which BDNF acts to modulate respiratory rhythmogenesis.

\section{Respiratory-related effects of BDNF include potentiation of excitatory synaptic currents and changes in voltage- dependent properties of PBC neurons}

In addition to decreasing the respiratory frequency generated by the PBC network, application of exogenous BDNF increased rhythmic excitatory synaptic drive in individual PBC neurons. These data are consistent with previous findings that increasing excitatory synaptic coupling results in a decrease in respiratory frequency in the PBC (Butera et al., 1999; Del Negro et al., 2001). In other systems, BDNF has been shown to increase synaptic strength through actions at presynaptic and postsynaptic sites (for review, see Huang and Reichardt, 2001). Our observation that BDNF enhanced glutamate evoked currents in PBC neurons indicates that the neurotrophin may increase synaptic coupling in this system through a postsynaptic action, although a possible presynaptic contribution cannot be ruled out.

Our results also identify, for the first time, the $I_{\mathrm{h}}$ current as a target of BDNF signaling. Specifically, BDNF application caused a reduction of $I_{\mathrm{h}}$ amplitude and a negative shift in the $I_{\mathrm{h}}$ activation curve in PBC neurons. As observed in other areas of the CNS (Bal and McCormick, 1997; Luthï and McCormick, 1998; Fortin et al., 1999), the reduction in $I_{\mathrm{h}}$ amplitude induced by BDNF was associated with a decrease in the frequency of network activity; however, blocking the $I_{\mathrm{h}}$ current in brainstem slices was shown previously to increase respiratory frequency in the PBC (Thoby-Brisson et al., 2000). This apparent discrepancy could be explained by the fact that, unlike pharmacologic blockade of $I_{\mathrm{h}}$, BDNF modulates $I_{\mathrm{h}}$ in only a 
subset of neurons involved in respiratory rhythmogenesis. Moreover, BDNF may act differently on different cells, as in the cortex (Rutherford et al., 1998), and the net result is a decrease in frequency. Further experiments are required to determine, for example, whether BDNF also influences the activity of inspiratory neurons exhibiting pacemaker properties.

\section{The PBC is a possible source of BDNF}

Among 16 cells analyzed by RT-mPCR, 6 expressed BDNF mRNA, of which 2 coexpressed BDNF and TrkB receptor $\mathrm{mR}$ NAs. This suggests that $\mathrm{PBC}$ neurons themselves may release BDNF; however, treatment of slices with the tyrosine receptor kinase inhibitor K252a alone did not alter the frequency of PBC output, indicating that endogenous BDNF does not influence network activity under resting conditions. Given that neurotrophin release is activity dependent and that high-frequency stimulation is most effective at releasing BDNF (Balkowiec and Katz, 2002), additional experiments are needed to define conditions under which BDNF may be secreted by PBC neurons. Nonetheless, the fact that some PBC neurons express both BDNF and TrkB mRNA raises the possibility of autocrine as well as paracrine actions of BDNF within the respiratory pattern generator.

\section{References}

Bal T, McCormick DM (1997) Synchronized oscillations in the inferior olive are controlled by the hyperpolarization-activated cation current $I(\mathrm{~h})$. J Neurophysiol 77:3145-3156.

Balkowiec A, Katz DM (1998) Brain-derived neurotrophic factor is required for normal development of the central respiratory rhythm in mice. J Physiol (Lond) 510:527-533.

Balkowiec A, Katz DM (2002) Cellular mechanisms regulating activitydependent release of native brain-derived neurotrophic factor from hippocampal neurons. J Neurosci 22:10399-10407.

Bianchi Al, Denavit-Saubie M, Champagnat J (1995) Central control of breathing in mammals: neuronal circuitry, membrane properties and neurotransmitters. Physiol Rev 75:1-45.

Blum R, Kafitz KW, Konnerth A (2002) Neurotrophin-evoked depolarization requires the sodium channel Nav1.9. Nature 419:687-692.

Butera RJ, Rinzel JJ, Smith JC (1999) Model of respiratory rhythm generation in the pre-Bötzinger complex. II. Population of coupled pacemaker neurons. J Neurophysiol 81:398-415.

Cauli B, Audinat E, Lambolez B, Angulo M-C, Ropert N, Tsuzuki K, Hestrin S, Rossier J (1997) Molecular and physiological diversity of cortical nonpyramidal cells. J Neurosci 17:3894-3906.

Del Negro CA, Johnson SM, Butera RJ, Smith JC (2001) Models of respiratory rhythm generation in the pre-Bötzinger complex. III. Experimental tests of model predictions. J Neurophysiol 86:59-74.

Erickson JT, Conover JC, Borday V, Champagnat J, Barbacid M, Yancopoulos G, Katz DM (1996) Mice lacking brain-derived neurotrophic factor exhibit visceral sensory neuron losses distinct from mice lacking NT4 and display a severe developmental deficit in control of breathing. J Neurosci 16:5361-5371.

Fortin G, Jungbluth S, Lumsden A, Champagnat J (1999) Segmental speci- fication of GABAergic inhibition during development of hindbrain neural networks. Nat Neurosci 2:873-877.

Gray PA, Rekling JC, Bocchiaro CM, Feldman JL (1999) Modulation of respiratory frequency by peptidergic input to rhythmogenic neurons in the pre-Bötzinger complex. Science 286:1566-1568.

Gray PA, Janczewski WA, Mellen N, McCrimmon DR, Feldman JL (2001) Normal breathing requires pre-Bötzinger complex neurokinin-1 receptor-expressing neurons. Nat Neurosci 4:927-930.

Huang EJ, Reichardt LF (2001) Neurotrophins: roles in neuronal development and function. Annu Rev Neurosci 24:677-736.

Koshiya N, Guyenet PG (1998) Tonic sympathetic chemoreflex after blockade of respiratory rhythmogenesis in the rat. J Physiol (Lond) 491:859-869.

Lambolez B, Audinat E, Bochet P, Crepel F, Rossier J (1992) AMPA receptor subunits expressed by single Purkinje cells. Neuron 9:247-258.

Lu B (2003) BDNF and activity-dependent synaptic modulation. Learn Mem 10:86-98.

Luthï A, McCormick DM (1998) Periodicity of thalamic spindle waves is abolished by ZD7288, a blocker of $I_{\mathrm{h}}$. J Neurophysiol 79:3284-3289.

Magee JC (1998) Dendritic hyperpolarization-activated currents modify the integrative properties of hippocampal CAl pyramidal neurons. J Neurosci 18:7613-7624.

Mironov SL, Langohr K, Richter DW (2000) Hyperpolarization-activated current, $I_{\mathrm{h}}$, in inspiratory brainstem neurons and its inhibition by hypoxia. Eur J Neurosci 12:520-526.

Ramirez JM, Quellmalz UJA, Richter DW (1996) Postnatal changes in the mammalian respiratory network as revealed by the transverse brainstem slice preparation of mice. J Physiol (Lond) 491:799-812.

Ramirez JM, Telgkamp P, Elsen FP, Quellmalz UJ, Richter DW (1997) Respiratory rhythm generation in mammals: synaptic and membrane properties. Respir Physiol 1110:71-85.

Ramirez JM, Schwarzacher SW, Pierrefiche O, Olivera BM, Richter DW (1998) Selective lesioning on the cat pre-Bötzinger complex in vivo eliminates breathing but not gasping. J Physiol (Lond) 507:895-907.

Rekling JC, Feldman JL (1998) Pre-Bötzinger complex and pacemaker neurons: hypothesized site and kernel for respiratory rhythm generation. Annu Rev Physiol 60:385-405.

Rekling JC, Champagnat J, Denavit-Saubie M (1996) Electroresponsive properties and membrane potential trajectories of three types of inspiratory neurons in the newborn mouse brain stem in vitro. J Neurophysiol 75:795-810.

Rutherford LC, Nelson SB, Turrigiano GG (1998) BDNF has opposite effects on the quantal amplitude of pyramidal neuron and interneuron excitatory synapses. Neuron 21:521-530.

Santoro B, Chen S, Luthï A, Pavlidis P, Shumyatsky GP, Tibbs GR, Siegelbaum SA (2000) Molecular and functional heterogeneity of hyperpolarization-activated pacemaker channels in the mouse CNS. J Neurosci 20:5264-5275.

Smith JC, Ellenberger HH, Ballanyi K, Richter DW, Feldman JL (1991) PreBötzinger complex: a brainstem region that may generate respiratory rhythm in mammals. Science 254:726-729.

Thoby-Brisson M, Telgkamp P, Ramirez JM (2000) The role of the hyperpolarization-activated current in modulating rhythmic activity in the isolated respiratory network of mice. J Neurosci 20:2994-3005.

Wang WG, Stornetta RL, Rosin DL, Guyenet PG (2001) Neurokinin-1 receptor-immunoreactive neurons of the ventral respiratory group in the rat. J Comp Neurol 434:128-146. 